TENDENCIAS

Revista de la Facultad de Ciencias

Económicas y Administrativas.

Universidad de Nariño

ISSN-E 2539-0554

Vol. XXI No. 2 - 2do Semestre 2020,

Julio-Diciembre - Páginas 19-44

\title{
ANÁLISIS DE LA COMPETITIVIDAD DE LAS EXPORTACIONES DEL CAFÉ DEL HUILA $^{1}$
}

\author{
ANALYSIS OF THE COMPETITIVENESS OF HUILA COFFEE EXPORTS \\ ANÁLISE DA COMPETITIVIDADE DAS EXPORTAÇÕES DE CAFÉ HUILA
}

CERQUERA LOSADA_ Oscar Hernán; PÉREZ GÓMEZ_ Víctor Hugo;

SIERRA CHAVARRO_ Jakeline

Magíster en Economía, Universidad de Buenos Aires, Argentina. Docente tiempo completo de planta del programa de Economía, Universidad Surcolombiana. E-mail: oscar.cerquera@usco.edu.co, Colombia.

Magíster en Pensamiento Estratégico y Prospectiva, Universidad Externado de Colombia. Director Regional, Cámara de Comercio de Neiva sede Garzón. E-mail: victorhugoperezgo@gmail.com, Colombia.

Magíster en Administración de Empresas, Universidad de Viña del Mar, Chile, Profesional grado 6 del SENA, Regional Huila. E-mail: jakeline.sierra@usco.edu.co, Colombia.

Recibido: 6 de marzo de 2020

Aprobado: 7 de julio de 2020

DOI: https://doi.org/10.22267/rtend.202102.139

\section{RESUMEN}

El café ha logrado consolidarse como uno de los productos más importantes del departamento del Huila, siendo reconocido como el principal productor de Café en Colombia, tanto así, que es un producto priorizado en la Apuesta Agroindustrial de la Agenda Interna de Productividad y

\footnotetext{
${ }^{1}$ Artículo de investigación, financiado por la Vicerrectoría de Investigación mediante convocatoria interna No. 01 de 2018 para conformar el banco de proyectos de investigación, desarrollo e innovación, menor cuantía, en la modalidad de financiación, dirigida a los grupos de investigación de la Universidad Surcolombiana.
} 
Competitividad del Huila. Por lo anterior, analizar el estado actual de la competitividad exportadora de dicho producto es relevante no solo para el sector agroindustrial del Huila sino también de todo el país. Por tal razón, el propósito de este trabajo es determinar el nivel de competitividad del café del Huila, a través del índice de ventaja comparativa revelada y estudiar sus determinantes mediante la estimación de un modelo de regresión múltiple. Los análisis de los indicadores mostraron que el Huila tiene una gran ventaja en la exportación de café; y que los países con los que presenta mayor complementariedad comercial son Estados Unidos y los países de la Unión Europea. Los principales determinantes de la competitividad son el tipo de cambio del dólar, mientras que el producto interno bruto, el precio del café y la tasa de desempleo, se relacionan negativamente con la competitividad exportadora del café del Huila.

Palabras clave: ventaja comparativa revelada; intensidad importadora; complementariedad comercial; apuestas productivas; acuerdo comercial; competitividad.

JEL: B23; C01; D13; E23; F10; F50

\begin{abstract}
Coffee has managed to establish itself as one of the most important products in the department of Huila, being recognized as one of the main coffee producers in Colombia, so much so that it is a priority product in the Agroindustrial Bet of the Productive Schedule of the Department. Therefore, analyzing the current state of export competitiveness of said product is relevant not only for the agroindustrial sector of Huila but also for the entire country. For this reason, the purpose of this work is to determine the level of competitiveness of Huila coffee, through the revealed comparative advantage index and to study its determinants by modifying a multiple regression model. The analysis of the indicators showed that Huila has a great advantage in coffee exports; and that the countries with which it has the greatest commercial complementarity are the United States and the countries of the European Union. The main determinants of competitiveness are the dollar Exchange rate, while the gross domestic product, the price of coffee and the unemployment rate, are negatively related to the export competitiveness of Huila coffee.
\end{abstract}

Keywords: revealed comparative advantage; import intensity; commercial complementarity; productive bets; trade agreement; competitiveness.

JEL: B23; C01; D13; E23; F10; F50 


\section{RESUMO}

O café conseguiu se estabelecer como um dos produtos mais importantes no departamento de Huila, sendo reconhecido como um dos principais produtores de café da Colômbia, tanto que é um produto prioritário na Aposta Agroindustrial das Cronograma Produtivas do Departamento. Portanto, analisar o estado atual da competitividade das exportações desse produto é relevante não apenas para o setor agroindustrial de Huila, mas também para todo o país. Por esse motivo, o objetivo deste trabalho é determinar o nível de competitividade do café Huila, por meio do índice de vantagem comparativa revelado, e estudar seus determinantes, modificando um modelo de regressão múltipla. A análise dos indicadores mostrou que a Huila tem uma grande vantagem nas exportações de café; e que os países com os quais tem maior complementaridade comercial são os Estados Unidos e os países da União Europeia. Os principais determinantes da competitividade são a taxa de câmbio do dólar, enquanto o produto interno bruto, o preço do café e a taxa de desemprego, estão negativamente relacionados à competitividade das exportações do café Huila.

Palavras-chave: vantagem comparativa revelada; intensidade de importação; complementaridade comercial; apostas produtivas; acordo comercial; competitividade.

JEL: B23; C01; D13; E23; F10; F50

\section{INTRODUCCIÓN}

Desde la Apertura Económica de Colombia en la década de los 90, el país ha intentado insertarse en las principales corrientes comerciales del mundo, a través de los diferentes acuerdos comerciales que ha realizado con diferentes países o grupos de países; a la fecha Colombia tiene 15 Tratados de Libre Comercio vigentes, y 3 más suscritos; además cuenta con 19 Acuerdos Internacionales de Inversión, entre suscritos y vigentes. Esto le ha permitido al país, acceder a mayores oportunidades para aumentar sus niveles de competitividad y, de esta forma, acelerar el crecimiento y el desarrollo económico que conlleven a un aumento en el bienestar de la población.

Una de las estrategias para fomentar la competitividad del país, fue la implementación de la Agenda Interna para la Productividad y la Competitividad de Colombia² que se inició en el 2004 a partir de

\footnotetext{
${ }^{2}$ A partir del documento del Consejo de Política Económica y Social (Conpes) 3297 del 26 de julio de 2004.
} 
un proceso que se ha venido estructurando en los sectores más representativos de cada una de las regiones, con el propósito de diseñar una hoja de ruta con reformas, programas y proyectos prioritarios que garanticen el fomento la productividad y competitividad del país, así como aumentar y consolidar la participación en los mercados internacionales. Desde entonces, las apuestas productivas han sido utilizadas como criterio de priorización a la hora de proyectar la destinación de recursos e inversiones en las entidades territoriales. De acuerdo con el Departamento Nacional de Planeación (2007), las apuestas productivas son el conjunto de actividades y encadenamientos productivos con mayor potencial en el contexto del comercio internacional y con un mayor impacto sobre el crecimiento económico y el desarrollo social de los territorios.

El departamento de Huila, respondiendo al llamado del Gobierno Nacional, definió sus apuestas productivas en el marco del proyecto de la Agenda Interna de Productividad y Competitividad en 2005, y recientemente se redefinieron en el 2015, después de evaluar el nivel de cumplimiento de las metas propuestas para cada una de las apuestas productivas. El Departamento definió cinco apuestas, I) agroindustria de base tecnológica en cafés especiales y tradicionales, frutales, cacao y tabaco, II) turismo, III) piscicultura, IV) minería, en productos tales como el mármol, roca fosfórica, arcillas y oro, y V) energética, mediante una matriz energética diversificada e integrada por PCH's, energía solar y biomasa (CCN, 2015).

De acuerdo con Cerquera y Orjuela (2015), el café ha jugado un papel fundamental a lo largo de la historia del país, no solo por su importancia económica, sino también por su impacto en la vida social y cultural de los colombianos; el café ha traído significativos aportes al desarrollo económico, social e institucional del país, durante gran parte del siglo XX logró afianzar el crecimiento económico mediante la cantidad de las exportaciones, permitió el desarrollo de un mercado interno, promovió el transporte mediante la apertura de nuevas vías terrestres y la aparición del ferrocarril, y produjo un alto nivel de ocupación. Colombia es el tercer mayor productor de café del mundo, después de Brasil y Vietnam. La caficultura en Colombia sigue teniendo un papel fundamental en la economía nacional y sobre todo en las zonas rurales del país; de acuerdo con información del DANE durante el 2017 la participación del café en el PIB agropecuario de Colombia fue del 12,1\%, y en el PIB nacional del $0,8 \%$. 
La mayor parte del café se produce en alta montaña, sembrados a una altitud que llega a ser, en ocasiones, cercana a los 2000 metros sobre el nivel del mar (Machado, 2001). En el 53\% de los municipios del país se cultiva café, el cual genera más de 900.000 empleos rurales directos y aproximadamente 2 millones entre directos e indirectos. Actualmente existen más de 4.570 millones de árboles de café en más de 877.000 hectáreas, y 541.000 productores (Ministerio de Agricultura y Desarrollo Rural, 2019). Actualmente, el tamaño promedio de una finca productora de café es de 1,3 hectáreas, mientras que el caficultor cultiva en promedio, 1,6 hectáreas; esto indica que la producción de café en Colombia, continúa siendo de pequeños productores. De las 877.000 hectáreas cultivadas en café, para el año 2018, el 85\% correspondió a hectáreas de café tecnificado joven, el 13\% a café tecnificado envejecido, y el $2 \%$ restante a caficultura tradicional; este importante porcentaje de café tecnificado joven, se debe en buena medida al apoyo del Servicio de Extensión de la Federación Nacional de Cafeteros (FNC, 2018). Por otra parte, el sector cafetero representa el primer renglón de exportaciones agrícolas del país, exportando aproximadamente el $92 \%$ del total de café que se produce en Colombia. Durante el 2018 se exportaron 12.751 sacos de $60 \mathrm{~kg}$ de café verde, lo que representó un ingreso de divisas a la economía colombiana de 2.614 millones de dólares. Del total de exportaciones, el $88,7 \%$ correspondió a café verde, el 6,1\% extracto y soluble, el 4,3\% café verde industrializado, el $0,5 \%$ café tostado molido y por último el $0,3 \%$ correspondió a café tostado en grano. De acuerdo con el destino de exportación, Estados Unidos es el principal comprador de café con el $48 \%$; Europa importa cerca del $26 \%$ del total del café colombiano, llegando principalmente a países como Alemania (9\%), Bélgica (5\%), Italia (3\%) y España (2\%). Países como Japón y Canadá importan cada uno el 9\% del café de Colombia; Corea del Sur (4\%), Australia (2\%) y Finlandia (2\%), fueron otros de los países importadores de café durante el 2018.

De acuerdo con cifras de la Federación Nacional de Cafeteros (2018), el principal productor de café verde de Colombia es el departamento de Huila, con el 18\% del total del área cultivada en el país, y un rendimiento departamental de 1,1 toneladas por hectárea (ton/ha); de ahí la importancia de centralizar este estudio en el café huilense. Antioquia es el segundo mayor productor con el 16\% del total de producción, y un rendimiento de 1,08 ton/ha; seguido del Tolima con el 14\% y un rendimiento departamental de 1,6 ton/ha, y el Cauca con el 10\% del total del área cultivada y un rendimiento promedio del 1,02 ton/ha. 
En el 2018, el departamento del Huila presentó un total de 146.763 hectáreas sembradas de café. Sin embargo, preocupa el hecho que durante el 2018 disminuyó en 2,37\% la participación a nivel nacional en el total de hectáreas sembradas con respecto al 2017. A nivel departamental, el 90,2\% del área sembrada corresponde a cultivos menores o iguales a 12 años (tecnificado), el 9,6\% a cultivos mayores a 12 años (Tecnificado Envejecido), y el 0,13\% a cultivos típicos con densidad menor a 2.500 árboles (Tradicional). En cuanto a las exportaciones totales, durante el 2018 el Huila exportó un total de \$US 473.2 millones a precio FOB, con una variación de $0,07 \%$ con respecto al año anterior; café sin tostar y sin descafeinar $(85,37 \%)$ es el producto que más se exportó, seguido de filetes de tilapia, fresco o refrigerados que participó con el 9,36\% y aceites crudos de petróleo o de mineral bituminoso con el (2,02\%). Estados Unidos es el principal receptor mundial del café huilense (46,04\%), seguidos de la Unión Europea (24,17\%), Canadá (7,97\%), Japón (7,61\%), y Corea del Sur (3,06\%).

De acuerdo con el Informe de Coyuntura Económica emitido por la Cámara de Comercio de Neiva (2018), se destaca la actividad cafetera como uno de los principales renglones productivos que le genera al Departamento aproximadamente 110.000 empleos directos, y más de 27.000.000 de jornales por año. Durante 2018, el cultivo de café en el Huila fue valorado en 928.000 millones de pesos, representando el 48,77\% del PIB agrícola, el 34,39\% del PIB agropecuario y el 5,9\% del PIB total ${ }^{3}$.

Dada la importancia del café, no solo para el departamento del Huila sino también para Colombia, surge la inquietud de estudiar que está ocurriendo con la competitividad de este importante producto. Por lo anterior, el propósito de este artículo es medir la competitividad del café, como producto priorizado en las apuestas productivas del departamento del Huila, a través del índice de ventaja comparativa revelada para el periodo 2009-2018, y determinar cuáles han sido las principales variables que han afectado está competitividad. Además, teniendo en cuenta los Tratados de Libre Comercio que actualmente están vigentes en Colombia, se determinó cuáles son los potenciales socios comerciales (países y grupo de países) para el Huila en la comercialización de café.

La competitividad del café se midió a través del Índice de Ventaja Comparativa Revelada (ICVR) que determina el potencial exportador de un producto; posteriormente, se identificó los países que mayor

\footnotetext{
${ }^{3}$ Estas cifras se obtuvieron de la Evaluación Agropecuaria del Departamento del Huila del 2018, y las Cuentas Nacionales Departamentales del DANE para el mismo periodo.
} 
demandan café, en el marco de los TLC firmados por Colombia, a través del Índice de Intensidad Importadora (III), y mediante el Índice de Complementariedad Comercial (ICC), se determinó cuáles son los países con los que el Huila presenta mayor complementariedad comercial en la mercantilización del café. La identificación de las variables que determinan la competitividad del café, se logró mediante un modelo de regresión lineal múltiple, que determinó el efecto de un conjunto factores sobre en el indicador de competitividad del cafét para el departamento del Huila.

\section{REFERENTES TEÓRICOS}

La Teoría de la Ventaja Comparativa Revelada, es uno de los conceptos básicos de la economía internacional que parte de los planteamientos de David Ricardo. Hacia mediados del siglo XX, algunos autores -Liesner (1958), Balassa (1965), Vollrath (1991), Scott y Vollrath (1992)-, empezaron a utilizar datos de estadísticas de comercio internacional para diferentes países o regiones, con el propósito de evaluar sus ventajas o desventajas comparativas en un determinado producto.

Balassa (1965), uso el término "Ventaja Comparativa Revelada" con el propósito de indicar que, los países pueden revelar las ventajas comparativas a través del comercio de mercancías, ya que el intercambio real de bienes muestra que existen diferencias entre los países y sus costros relativos, que se explican no necesariamente por características del mercado.

De acuerdo con Tsakok (1990), existen dos conceptos de ventaja comparativa revelada globalmente aceptados; en el primero, compara la eficiencia de la producción de un par de territorios, a partir del costo de oportunidad, por lo tanto, el país que presente el costo de oportunidad más bajo será relativamente más eficiente y, por lo que, presenta cierta ventaja en la producción de un determinado bien. La eficiencia relativa puede depender de aspecto como la utilización de una menor cantidad de insumos por unidad de producto, el uso de menos recursos domésticos, menores costos de oportunidad en los recursos domésticos, o la devaluación de la moneda local. El segundo concepto hace referencia, a la eficiencia en la producción de diferentes bienes al interior de cada país, en donde estos bienes se comparan en términos de sus ganancias y ahorro por unidad de divisas utilizadas.

\footnotetext{
${ }^{4}$ Este indicador se calculó con base en el Índice de Ventaja Comparativa Revelada de Vollrath.
} 
La Ventaja Comparativa Revelada estima el comportamiento relativo de las exportaciones de un país o sector, y se define como la participación de un país en las exportaciones mundiales de un bien dividido por su participación en las exportaciones mundiales totales. Es decir, el índice permite conocer las especializaciones exportadoras de un país o región.

Chudnovsky y Porta (1990), sostiene que la teoría de las ventajas comparativas reveladas hace parte de la teoría del comercio internacional. En los escritos actuales sobre el tema, se plantea que mientras mayor abundancia relativa de factores tengan los países, mayor flujo de productos se presenta, por lo que cada país se especializa en producir y exportar los productos en los cuales utiliza los factores relativamente más abundantes que poseen.

Es importante aclarar que el índice mostrado no solamente se utiliza con datos de exportaciones, el análisis también puede extenderse con datos sobre importaciones de un país, calculo conocido como Índice de Intensidad Importadora (III), que mide la importancia que tiene la importación de un determinado bien o sector dentro de la producción total. Con este índice se puede comparar la proporción de las importaciones de un determinado sector en un país, con la proporción de las importaciones de ese sector o producto en el mercado mundial. Del mismo modo, es posible determinar el grado de complementariedad comercial (ICC) entre dos países, basta con calcular el producto entre el índice de la ventaja comparativa revelada de un país y el índice de intensidad importadora del otro país para un mismo producto.

Si un país exporta con mayor éxito un determinado bien, esto implica que la economía en cuestión tiene un conjunto de ventajas competitivas y comparativas respecto del mundo, y estas ventajas pueden deberse, según Celaya (2005), a factores como la especialización en los procesos, la formación del recurso humano, la disponibilidad de recursos materiales, al contexto regulador del intercambio, y a la capacidad de generar o atraer recursos financieros. En la teoría de las ventajas comparativas se argumenta que un territorio no debe intentar exportar cualquier bien o producto que produzca de manera eficiente, sino que también debe en cuenta la demanda mundial, y de esta forma evaluar que podría exportar, para posteriormente generar las condiciones internas adecuadas que le permitan producir de manera eficiente (Celaya, 2005). Es importante tener en cuenta, que la competitividad internacional no se produce a partir de ventajas naturales, estas son el producto de un conjunto de 
estrategias coherentes, que define una política clara orientada a la exportación. En este sentido, el papel del Estado debe complementar el papel de la economía, que ayude a desarrollar nuevas ventajas competitivas.

Muchos estudios se han realizado alrededor del análisis de indicadores de Ventaja Comparativa Revelada. Rendón y Morales (2001), realizaron un modelo de regresión múltiple con mínimos cuadrados ordinarios para encontrar los determinantes de las ventajas comparativas en la industria del calzado en México; los autores concluyen que la tasa de cambio real tiene una elasticidad positiva por lo que favorece la competitividad del sector. También analizan la relación inversa entre el PIB y la competitividad; demuestran que, tras la apertura económica del país, se empezaron a importar calzado en los años 1985- 1996.

Cerda, Alvarado, García y Aguirre (2008), realizaron un modelo determinístico para demostrar la relación que tiene la competitividad del vino chileno y el PIB real, junto con la tasa de cambio real y el precio del vino durante los años 1985-2002. Los autores desarrollaron tres modelos con diferentes índices de ventajas comparativas reveladas de acuerdo a los cuatro productores principales mundiales de vino: Francia, Italia, España y Estados Unidos. Se concluye que el modelo de índice de ventajas comparativas reveladas de Vollrath presenta estimaciones más robustas por su naturaleza de logaritmo; los autores también demuestran que la tasa de cambio real y el PIB real, se relacionan de manera positiva con el índice de competitividad del vino, al igual que una relación negativa de este mismo índice con el precio chileno.

De nuevo Cerda, García, Aguilera y Villagrán (2011), hallaron los determinantes de la competitividad de las exportaciones de uva de mesa chilena, durante el periodo 1984-2004. El objetivo del estudio es determinar el nivel de competitividad de la uva de mesa de Chile, utilizando del índice de Vollrath. Los autores encuentran que hasta el 2002, la competitividad fue creciente; así mismo encontraron que el tipo de cambio real y el producto interno bruto real son los principales determinantes de la competitividad de la uva de mesa chilena.

En otro estudio, llevado a cabo por Khaksar (2014), se investigaron las tendencias de exportación y los índices de ventaja comparativa revelada para frutas como cerezas, ciruelas, melocotones y 
albaricoques en Irán durante 1997 a 2010. Los resultados mostraron que Irán tenía ventaja comparativa de las exportaciones de frutas sólo en 2007 y 2010. Sin embargo, este índice tuvo un crecimiento positivo para las frutas en esos años, lo que indica una tendencia creciente en el estado de exportación de estos productos. El análisis permitió identificar que los principales mercados de exportación para Irán en los productos estudiados fueron Alemania, Reino Unido, Francia, Italia, Países Bajos, Rusia, Arabia Saudita, Bahrein, Suiza, Emiratos Árabes Unidos y Afganistán.

Villablanca (2014), estudio el comportamiento de la competitividad de la industria de vinos de chile durante el periodo1994-2013, con respecto a los mercados del Reino Unido y Norteamérica. El autor empleo la metodología de las ventajas comparativas reveladas para determinar la posición que ocupa Chile en los dos países analizados. Dicho análisis se realizó sobre los tres principales segmentos que componen la industria del vino, a saber, vinos espumosos, embotellados y a granel. Como resultado de la investigación el autor encontró que la industria de vinos chilena es competitiva en los segmentos de vinos embotellados y a granel, tanto en Estados Unidos como en Reino Unido.

Obadi y Korcek (2016), examinaron la ventaja comparativa revelada y la especialización del comercio internacional en la Unión Europea (UE) y Estados Unidos. Los autores encontraron que, si bien con base en el índice de la ventaja comparativa de Balassa, la UE ha alcanzado una ventaja comparativa en un grupo más pequeño de productos (32 de 66) que Estados Unidos (40 de 66), la UE no sólo ha alcanzado una ventaja comparativa en más industrias, sino también una tendencia más estable de especialización internacional que los EE.UU.

El presente artículo, analiza la competitividad exportadora de un producto como el café, el cual es sumamente importante para el Huila y Colombia. Lo interesante de este artículo es que define un listado de países, con los cuales Colombia tiene firmados TLC's, en los que el Huila puede priorizar sus esfuerzos de exportación, pues son países con los que el Huila se complementa comercialmente. Este artículo se convierte en el primero, a nivel departamental, que estudia este tipo de temáticas en un producto tan importante como el café. 


\section{METODOLOGÍA}

Con el propósito de identificar la competitividad exportadora del café en el departamento del Huila, como producto priorizado en la Agenda Interna de Productividad y Competitividad del Departamento, la metodología empleada se divide en dos partes. En la primera, se analizan las ventajas comparativas del café del Huila frente a las necesidades de demanda de los 15 países y/o grupo de países con los que Colombia tiene firmado algún TLC; estos cálculos se realizaron para el periodo 2015-2018. En la segunda parte, se realiza un análisis de regresión múltiple, que incorpora variables que afectan la competitividad de las exportaciones del café durante el periodo 2009-2018.

Los datos a nivel mundial provienen de la base de datos Trade Map que contiene información para los diferentes países del mundo de acuerdo a la posición arancelaria de cada uno de los productos. La información de las exportaciones de café del departamento del Huila proviene de la base de datos Legiscomex, que recoge información de comercio exterior de toda Colombia. En este artículo se tuvo en cuenta información de las exportaciones e importaciones del Huila, de los países que tienen TLC firmado con Colombia, y del mundo. Dicho reporte se realizó con base en el Sistema Armonizado a nivel de subpartidas arancelarias (seis dígitos) de 2017. Las exportaciones e importaciones vienen dadas a precios FOB.

Para identificar la potencialidad exportadora del café, se estimaron los siguientes índices:

\section{- Índice de Ventaja Comparativa Revelada (IVCR)}

Este índice compara la proporción de las exportaciones de un bien en un país o región, con la proporción de las exportaciones de ese mismo bien a nivel mundial. El propósito es identificar sí un determinado bien es competitivo en las corrientes mundiales de intercambio de bienes. El IVCR puede tomar valores mayores a uno, o menores a uno. En el primer caso, indica que el país muestra cierta competitiva en el mercado internacional con respecto a la comercialización de un producto en particular. En el segundo caso, muestra que el país no es competitivo en ese producto.

$$
\operatorname{IVCR}_{i j}=\left(X_{i j} / X_{i}\right) /\left(X_{w j} / X_{w}\right)
$$


Donde, el subíndice i representa el país o región en cuestión, el subíndice w representa el mundo y el subíndice j el producto o sector analizado; $I V C R_{i j}$ representa el Índice de Ventaja Comparativa Revelada del país i para el producto j, y las X muestran tanto las exportaciones totales del país o región $\left(X_{i}\right)$, del mundo $\left(X_{w}\right)$, del país en estudio sobre el bien en particular $\left(X_{i j}\right)$, y del mundo también sobre el producto en cuestión $\left(X_{w j}\right)$.

\section{- Índice de Intensidad Importadora (III).}

El III establece los bienes que más importa un país o región, pues compara la proporción de las importaciones de un bien en un país o región, con la proporción de las importaciones de ese mismo bien a nivel mundial. Sí el índice es mayor a uno, indica que el país o región importa de manera significativa el bien analizado, ya que, en términos relativos, dicho país importa una proporción mayor de este bien, que la que se importa a nivel mundial.

$$
I I I_{i j}=\left(M_{i j} / M_{i}\right) /\left(M_{w j} / M_{w}\right)
$$

Donde, los subíndices i, j y w representan lo mismo en que en la ecuación (1), $I I I_{i j}$ muestra el Índice de Intensidad Importadora del país i para el producto j, en este caso las M representan las importaciones del país o región $\left(M_{i}\right)$, del mundo $\left(M_{w}\right)$, del país en estudio sobre el bien en particular $\left(M_{i j}\right)$, y del mundo también sobre el producto en cuestión $\left(M_{w j}\right)$.

- Índice de Complementariedad Comercial (ICC)

El ICC indica el nivel de asociación entre lo que exporta un país o región y lo que importa otro país, con respecto a un mismo bien. El ICC resulta de la multiplicación del IVCR del país exportador y el III del país importador.

$$
I C C_{A B j}=I V C R_{A} * I I I_{B}
$$

Donde, $I C C_{A B j}$ indica el Índice de Complementariedad Comercial, entre el país A y el país B para el producto j, el $I V C R_{A}$ presenta Ventaja Comparativa Revelada, ecuación (1), del país A, y el $I I I_{B}$ hace referencia a la Intensidad Importador, de la ecuación (2), del país B. 
Dos países o regiones tendrán complementariedad comercial sí el ICC es mayor que 1; en este caso, un país A se especializa en la exportación de un determinado bien (IVCR>1), mientras que el país B se especializa en la importación del mismo bien (III>1). En este caso se dice que existe una potencialidad exportadora inmediata. Sin embargo, también puede existir complementariedad comercial entre dos países o regiones, así alguno de los dos índices (IVCR y III) sean inferiores a 1. Cuando esto ocurre, el índice que es mayor la unidad, está compensando más que proporcionalmente el otro índice.

De acuerdo con Cerquera, Giraldo y Córdoba (2017), la complementariedad bilateral se da cuanto un país presenta ventaja comparativa en un determinado producto, que el otro país no produce de manera eficiente, por lo que debe importarlo de manera intensiva (III >1). Por el contrario, dos países compiten en la comercialización de un producto en particular, si los dos países presentan ventaja comparativa en los mismos productos.

El IVCR se estimó para el producto del café en el departamento del Huila, mientras que el III se midió para los 15 países o regiones con los cuáles Colombia tiene firmados TLC's. El ICC se calculó entre el Huila y cada uno de los 15 países o regiones, para el periodo 2015-2018.

Para determinar las variables que influencian la competitividad de las exportaciones del café, se estimó un modelo de regresión lineal múltiple a través del método de mínimos cuadrados ordinarios, con el propósito de determinar la incidencia de una serie de factores o variables en el indicador de competitividad de los principales productos exportados por el departamento del Huila. Como señala Verdoy, Mahiques y Pellicer (2006:54), "Las técnicas de regresión tienen por objeto modelizar, es decir, encontrar una función que aproxime lo máximo posible la relación de dependencia estadística entre variables y explicar los valores de una ellas".

En este caso, la variable explicativa corresponde al índice de la ventaja comparativa revelada de Vollrath (VCRv), que corresponde a la competitividad de las exportaciones del café del departamento del Huila; mientras que en las variables independientes o explicativas están incluidas el precio de venta del café, el tipo de cambio real de Colombia medido en pesos por dólar y el producto interno 
bruto del Huila. El periodo de estudio está comprendido entre 2009-2018, y la periodicidad de los datos es trimestral.

Las estimaciones se realizaron a través del software Eviews 10. El modelo queda definido como:

$$
V C R v_{\mathrm{i} t}=\beta_{0}+\beta_{1} \text { Precio }_{\mathrm{i} t}+\beta_{2} \text { TCRCol }_{t}+\beta_{3} \text { PIBHui }_{t}+\beta_{4} \text { TDesempleo }_{t}+\mu_{i}
$$

Donde, $V C R v_{\mathrm{i} t}$ represente el índice de la ventaja comparativa de Vollrath del café para el periodo t, Precio $_{\text {it }}$ representa el precio de café para el periodo t, TCRCol ${ }_{t}$ representa el tipo de cambio real de Colombia durante el periodo t, $\mathrm{PIBHui}$ r representa el producto interno bruto del Huila para el periodo $\mathrm{t}$, TDesempleo $t$ indica la tasa del desempleo del Huila para el periodo $t, \mu_{i}$ indica el error aleatorio del modelo.

El cálculo del índice de ventaja comparativa revelada de Vollrath (VCRv) se realizó con base en las exportaciones de cada uno de los productos identificados dentro de la Agenda Interna del Huila, para efectos de la comparación y evaluación de la competitividad.

El VCRv plantea una diferencia significativa entre un bien en particular y los demás productos comercializados por un país o región, y entre el país con el resto del mundo; este índice elimina la doble contabilidad de un producto y un país, pues se tienen en cuenta datos de importaciones y exportaciones de un producto, que representan la oferta y demanda de un determinado bien (Arias y Segura, 2004):

$$
V C R_{v}=V C E-V C I
$$

Donde $V C E$ y $V C I$ indican la ventaja comparativa revelada tanto de las exportaciones $(V C E)$ como de las importaciones $(V C I)$. A su vez, el $V C E$ y $V C I$ se expresan como sigue:

$$
\begin{aligned}
& V C E_{a}^{i}=\ln \left[\left(X_{a}^{i} / X_{n}^{i}\right) /\left(X_{a}^{r} / X_{n}^{r}\right)\right] \\
& V C I_{a}^{i}=\ln \left[\left(M_{a}^{i} / M_{n}^{i}\right) /\left(M_{a}^{r} / M_{n}^{r}\right)\right]
\end{aligned}
$$


Dónde X y M representan las exportaciones y las importaciones respectivamente, i es el país/región en observación, en este caso el departamento del Huila, $a$ es el bien en análisis, en este caso el café, $r$ se refiere al resto de países del mundo, mientras que $n$ se indica el comercio de todos los bienes menos el bien en análisis (bien $a$ ). Este índice permite hacer comparaciones de ventaja comparativa entre diferentes productos, por lo que, mientras más alto sea el VCRv de un bien en particular, mayor es la competitividad de este producto en el mercado internacional. De esta manera, si VCE > 0 o VCI $<0$, el país muestra ventaja comparativa en las exportaciones e importaciones de un producto, mientras que si VCE $<0$ o VCI $>0$, el país muestra desventaja comparativa. En este caso, se estimarán tantos índices como productos exporte el Huila.

Con respecto al PIB del Huila, debido a que no se cuenta con información trimestral del PIB por departamento, se estimó una variable proxy del PIB departamental trimestral, la cual se calculó teniendo en cuenta la participación del PIB departamental anual en el PIB nacional; está participación se estimó a nivel trimestral, en este caso para el departamento del Huila. La tasa de cambio se toma de las estadísticas proporcionadas mensualmente por el Banco de la Republica de Colombia, estos datos se convirtieron a trimestrales. Para la variable Precio del Café, se toman los precios proporcionados por la base de datos del Legiscomex del kilogramo de Café en Dólares, y se hace un promedio para encontrar el precio trimestral. Estas estimaciones se realizaron teniendo en cuenta un nivel de significancia del 95\%, o lo que es equivalente, un margen de error del 5\%.

\section{DISCUSIÓN}

La primera parte de la discusión, está compuesta por la estimación de Índice de Ventajas Comparativas Reveladas (IVCR) del café en el departamento del Huila durante los años 2015 al 2018. Se sigue con el análisis del Índice de Intensidad Importadora (III) de los países y grupos de países con los que Colombia tiene tratado de libre comercio vigente. Por último, con los índices anteriores se estima el Índice de Complementariedad Comercial (ICC) para el Departamento con cada uno de los países y grupos de países con los que existe un TLC vigente.

En la Tabla 1 se observa el IVCR para el café del departamento del Huila teniendo en cuenta las exportaciones totales durante el periodo 2015-2018, el III y ICC para para cada uno de los 15 tratados 
de libre comercio que tiene vigentes Colombia, y la potencialidad que tiene el café con cada uno de los tratados, en todos los casos, para el total del periodo 2015-2018.

Los resultados permiten afirmar que el café huilense es un producto competitivo en las corrientes mundiales de intercambio de bienes, pues al estimar el IVCR del café, se encontró que la participación de las exportaciones de café del Huila en las exportaciones mundiales café es 757,68 veces más grande en términos relativos, que la participación de las exportaciones totales (todos los productos) del Huila en las exportaciones mundiales totales. Es decir, el Huila está exportando más café, en términos relativos, al mundo, de lo que el Huila lo hace con el total de los demás productos.

\section{Tabla 1}

Índices de Ventaja Comparativa, 2015-2018

\begin{tabular}{lcccc}
\hline \multicolumn{1}{c}{ Países con TLC } & IVCR del Huila & III & ICC & Potencialidad \\
\hline México & 757,68 & 0,17 & 125,08 & Medio \\
El Salvador, & & & & \\
Guatemala y & 757,68 & 0,02 & 12,46 & Medio \\
Honduras & & & & \\
Chile & 757,68 & 0,57 & 428,91 & Medio \\
Canadá & 757,68 & 1,31 & 993,24 & Inmediata \\
Estados Unidos & 757,68 & 1,70 & 1287,76 & Inmediata \\
Venezuela & 757,68 & 1,86 & 1406,34 & Inmediata \\
Cuba & 757,68 & 2,92 & 2209,56 & Inmediata \\
Costa Rica & 757,68 & 0,61 & 460,69 & Medio \\
Corea del Sur & 757,68 & 0,84 & 634,26 & Medio \\
CAN- & 757,68 & 0,01 & 10,35 & Medio \\
Unión Europea & 757,68 & 3,34 & 2534,12 & Inmediata \\
EFTA & 757,68 & 1,76 & 1331,71 & Inmediata \\
Mercosur & 757,68 & 0,27 & 201,96 & Medio \\
Alianza del & 757,68 & 0,19 & 145,35 & Medio \\
pacifico & 757,68 & 0,08 & 62,41 & Medio \\
CARICOM & & & & \\
\hline
\end{tabular}

Fuente: elaboración propia.

En 6 de los 15 tratados de libre comercio firmados por Colombia, se presenta un III mayor a uno, indicando que tienen intensidad importadora en cafés. Los 28 estados miembros de la Unión Europea 
son los que mayor III presentan, lo que indica que la participación de las importaciones de la Unión Europea en café con respecto a las importaciones mundiales de café, son 3,34 veces más grandes en términos relativos, que la participación de las importaciones totales de la Unión Europea en las importaciones totales del mundo. Venezuela y Cuba también presentan una mayor intensidad importadora de café, sin embargo, el caso de Venezuela es especial, pues hasta el 2015 fue un gran importador del café, pero a partir de 2016 y debido al agudizamiento de la crisis venezolana, dejó de importar intensivamente café. Un aspecto importante es que este índice viene aumentando en los últimos años, como se evidencia en la Tabla 2.

\section{Tabla 2}

Cálculo de Indicadores por año y países o grupos de países, 2015-2018

\begin{tabular}{lrrrrrrrrrrrr}
\hline \multirow{1}{*}{\multicolumn{1}{c}{ Países }} & \multicolumn{3}{c}{2015} & \multicolumn{4}{c}{2016} & \multicolumn{3}{c}{2017} & \multicolumn{3}{c}{2018} \\
\cline { 2 - 12 } & IVCR & \multicolumn{1}{c}{ III } & \multicolumn{1}{c}{ ICC } & IVCR & III & ICC & IVCR & III & ICC & IVCR & III & \multicolumn{1}{c}{ ICC } \\
\hline México & 677,7 & 0,21 & 138,97 & 728,3 & 0,26 & 188,4 & 764,9 & 0,12 & 88,15 & 867,7 & 0,08 & 70,3 \\
El Salvador, & 677,7 & 0,03 & 18,41 & 728,3 & 0,05 & 32,96 & 764,9 & 0,00 & 1,62 & 867,7 & 0,00 & 2,8 \\
Guatemala y & & & & & & & & & & & & \\
Honduras & & & & & & & & & & & & \\
Chile & 677,7 & 0,44 & 297,31 & 728,3 & 0,42 & 309,1 & 764,9 & 0,50 & 384,8 & 867,7 & 2,24 & 1942,5 \\
Canadá & 677,7 & 1,20 & 812,99 & 728,3 & 1,28 & 933,7 & 764,9 & 1,39 & 1064,3 & 867,7 & 1,36 & 1183,3 \\
Estados Unidos & 677,7 & 1,68 & 1138,7 & 728,3 & 1,67 & 1216 & 764,9 & 1,74 & 1327,8 & 867,7 & 1,70 & 1474,0 \\
Venezuela & 677,7 & 3,36 & 2280,3 & 728,3 & 0,80 & 579,2 & 764,9 & 0,46 & 351 & 867,7 & 0,01 & 6,1 \\
Cuba & 677,7 & 2,37 & 1603,5 & 728,3 & 3,22 & 2342, & 764,9 & 3,14 & 2399,9 & 867,7 & 2,87 & 2486,3 \\
Costa Rica & 677,7 & 0,68 & 457,66 & 728,3 & 0,83 & 603,5 & 764,9 & 0,43 & 331,2 & 867,7 & 0,48 & 412,3 \\
Corea del Sur & 677,7 & 0,80 & 542,64 & 728,3 & 0,86 & 625,6 & 764,9 & 0,86 & 661,5 & 867,7 & 0,83 & 719,9 \\
CAN & 677,7 & 0,00 & 2,52 & 728,3 & 0,01 & 8,60 & 764,9 & 0,00 & 3,5 & 867,7 & 0,04 & 31,6 \\
Unión Europea & 677,7 & 3,45 & 2336,8 & 728,3 & 3,37 & 2455 & 764,9 & 3,31 & 2535,9 & 867,7 & 3,25 & 2820,2 \\
EFTA & 677,7 & 1,86 & 1258,6 & 728,3 & 1,57 & 1140 & 764,9 & 1,71 & 1311,2 & 867,7 & 1,89 & 1637,4 \\
Mercosur & 677,7 & 0,25 & 168,54 & 728,3 & 0,24 & 172,7 & 764,9 & 0,32 & 244,1 & 867,7 & 0,26 & 224,5 \\
Alianza del & 677,7 & 0,22 & 148,31 & 728,3 & 0,26 & 189,2 & 764,9 & 0,16 & 118,6 & 867,7 & 0,12 & 106,8 \\
pacifico & & & & & & & & & & & & \\
CARICOM & 677,7 & 0,12 & 80,51 & 728,3 & 0,09 & 64,86 & 764,9 & 0,07 & 53,9 & 867,7 & 0,05 & 45,6 \\
\hline
\end{tabular}

Fuente: elaboración propia.

Canadá y Estados Unidos, son países que también presentan intensidad importadora de café, aunque en menor proporción, las importaciones de café en dichos países se han mantenido relativamente estables durante todo el periodo de estudio. Chile es un caso particular, pues están empezando a 
consumir más café, durante el último año, durante el cual presentó una III mayor a uno, contrario a lo que ocurrió en los años anteriores.

En los demás países o grupos de países con los que Colombia tiene acuerdos comerciales vigentes, no se presentó intensidad importadora, lo que indica que el país en cuestión, no es el gran importador de café, lo que en cierta medida limitaría de manera inmediata, el acceso a dichos mercados. Del Mercosur y la CAN, hace parte Brasil, que es el principal productor de café del mundo, lo que explica el bajo nivel relativo de importaciones de café, además de países como Argentina, Uruguay y Paraguay, que culturalmente no tienen arraigado el consumo del café. Honduras, México y Guatemala, están entre los 10 principales productores de café del mundo; Perú, Nicaragua, Costa Rica y Ecuador, también son productores de café.

Debido a la intensidad importadora de países como Cuba, Canadá, Estados Unidos, el caso particular de Venezuela, y los grupos de países como la Unión Europea y el EFTA, el departamento del Huila, presenta un alto grado de complementariedad comercial (potencialidad inmediata) en la comercialización de café con cada uno de estos países con los cuales Colombia tiene firmados TLC. Las exportaciones de café hacia estos destinos, representa una gran oportunidad para el Huila, pues cada uno de los países y grupos de países, están interesados en importar dicho producto. De hecho, actualmente el Huila mantiene alguna relación comercial con estos países, Estados Unidos es el principal, a donde importó en 2018 cerca de 168.000.000 dólares a precios FOB en solo café. Hacía la Unión Europea el Huila exportó un total de 109.738.118 dólares de café. Los países de la EFTA (17.054.771 dólares) también importa café huilense, aunque en menor proporción, al igual que Canadá (37.695.578 dólares).

Por otro lado, con los demás países analizados también se presenta cierto grado de complementariedad comercial (potencialidad media), pero está se da, no por el lado del consumo, pues en dichos países las importaciones de café no son significativamente grandes, sino por el lado de la oferta, debido al potencial exportador del Huila. Por lo anterior, estos mercados, con los cuáles el país también tiene tratados de libre comercio vigentes, representan para el Huila un potencial destino de exportación, pero con menor facilidad de acceso en comparación con el primer grupo de países. No obstante, el Huila mantiene cierta relación comercial con algunos de estos países. Hacia Corea del Sur, el Huila 
exportó un total de 14,5 millones de dólares en 2018, mientras que hacia los países del Mercosur exportó cerca de 68.614 dólares a precios FOB.

En cuanto a las variables que afectan la competitividad, se empleó el método de mínimos cuadrados ordinarios. Además, se utilizó elasticidades en las variables independientes con el logaritmo. Para mostrar las significancias del modelo, se utilizó la prueba t para determinar la significancia de cada una de las variables y la prueba F para determinar la significancia conjunta.

Con respecto a la normalidad del modelo, con un valor chi-cuadrado de 0,85 y una probabilidad de 0,65 , la prueba de Jarque-Bera indica que no se rechaza la hipótesis nula de normalidad en los residuos, por lo que se concluye que los residuos se distribuyen de forma normal. Para verificar si hay multicolinealidad. se empleó el Factor de Inflación de la Varianza (VIF), el cual mostró que, en ninguna de las variables explicativas, se presenta un Factor de Inflación elevado, por lo tanto, el modelo no presenta problemas de multicolinealidad. Con un valor F-Statistic de 0,36, el test de Breusch-Pagan-Godfrey, para descartar heterocedasticidad, da como resultado una probabilidad de $\mathrm{p}=0,83$, por lo que no se puede rechazar la hipótesis nula de homocedasticidad, por lo tanto, se concluye que la varianza del residuo es constante. Finalmente, con el propósito de medir la autocorrelación de los residuos, el estadístico Dubin-Watson dió como resultado 1,469, por lo tanto, con un nivel de significancia del 5\% se puede concluir que no existe autocorrelación serial.

En lo relacionado al modelo en general, la variación del conjunto de las variables independientes, explican el 67\% de la variación de las ventajas comparativas del café en el departamento del Huila. Además, a nivel agregado, el modelo es globalmente significativo a cualquier nivel de significancia. Todas las variables incluidas en el modelo son significativas al 1\%, con excepción del logaritmo de la tasa de cambio, la cual es significativa al $5 \%$.

En la Tabla 3 se muestra que la tasa de cambio tiene un efecto directo en el índice de ventajas comparativas; por una variación del 1\% en la tasa de cambio del dólar con respecto al peso, el índice de competitividad aumenta en 3,7; esto se debe a que una mayor tasa de cambio incentiva las exportaciones, y por lo tanto la competitividad de los productos con potencial exportador. Con respecto a la tasa de desempleo del Huila, se evidencia una relación negativa con el índice de 
competitividad, por lo tanto, por un aumento del $1 \%$ en la tasa de desempleo departamental, el índice de ventajas comparativas de Vollrath disminuye en 6,16.

\section{Tabla 3}

Resultados del modelo econométrico

\begin{tabular}{lccc}
\hline Variables & Coef & Error Estándar & t-valor \\
\hline C & 71,435 & 12,87 & $5,547 * * *$ \\
Ln_PIBHui(-3) & $-9,052$ & 1,703 & $-5,314 * * *$ \\
Ln_TCRCol & 3,753 & 1,539 & $2,438^{* * *}$ \\
Ln_Precio(-3) & $-4,920$ & 1,095 & $2,438 * * *$ \\
Ln_Tdesempleo & $-6,168$ & 2,042 & $-3,019 * * *$ \\
\hline R2 & & 0,675 & \\
F-valor & & $16,651 * * *$ & \\
Observaciones & & 37 & \\
Durbin-Watson stat & & 1,469 & \\
\hline
\end{tabular}

Factor de Inflación de Varianza (VIF)

\begin{tabular}{lcc} 
& Ln_PIBHui(-3) & 2,99 \\
& Ln_TCRCol & 3,34 \\
& Ln_Precio(-3) & 1,49 \\
Jarque-Bera & Ln_Tdesempleo & 1,29 \\
\hline \multirow{2}{*}{ Breusch-Pagan-Godfrey } & Chi-cuadrado & Prob \\
& 0,859 & 0,650 \\
\hline
\end{tabular}

Notes: ***,**,* denotes $1 \%, 5 \%$, and $10 \%$ significance level, respectively.

Fuente: elaboración propia.

En cuanto a las variables PIB (a precios corrientes) y precio del café, las mismas se estimaron teniendo en cuenta tres periodos de rezagos para cada variable, demostrando que el efecto de estas variables no es inmediato en el tiempo. PIB y el precio del café, presentan una relación negativa con el índice de competitividad del café. Por un aumento del 1\% del PIB, el índice de competitividad disminuye en 9,05; esta relación negativa se explica porque el Huila, además de exportar café, a partir del 2012 empezó también a importa café, mientras que las exportaciones se mantuvieron relativamente constantes durante este periodo. Esto produjo que las exportaciones netas de café presentarán una variación pequeña pero negativa, lo que, de acuerdo con la teoría de la demanda agregada, disminuye 
el PIB. Por último, el coeficiente del precio del café, que muestra la elasticidad precio de la oferta, permite concluir que el café en el Huila es inelástico al cambio del precio, esto se debe a la gran dependencia de las exportaciones del café ${ }^{5}$ y la poca diversificación que tiene las exportaciones del Huila. Además, debido a que el precio del café es determinado a nivel internacional, y debido a que el mismo fluctúa constantemente, los productores de café son precio aceptante, y su producción, en términos generales, se mantienen en los mismos niveles, independientes del precio actual del mercado.

Sin lugar a dudas, el café del departamento del Huila, es un producto que presenta un alto nivel de competitividad exportadora, lo que indica que es un producto competitivo en las corrientes mundiales de intercambio de bienes, es decir, las exportaciones de café, en comparación con otros productos, son relativamente mayores tanto a nivel departamental como a nivel mundial; esto se debe fundamentalmente a la importancia del cultivo del café para el Departamento, en donde el Huila es el mayor productor a nivel nacional, y es el café, que mayoritariamente exporta el Departamento.

Por tal razón, el café es un producto que se encuentra priorizado en la Agenda Interna de Competitividad no solo del Huila, sino de varios departamentos del país, pues un poco más de la mitad de los municipios colombianos son productores de café, convirtiéndose en una fuente importante de empleo, en especial a nivel rural. El café está impregnado en la cultura de Colombia, la producción cafetera ha acompañado, y en muchas ocasiones gestionado, el desarrollo económico y social del país.

Los tratados de libre comercio, son objeto de diversas controversias. Sin embargo, en lo relacionado con el café, es importante precisar que el Huila exporta café a más de la mitad de los países con los cuales Colombia ha firmado algún acuerdo comercial; esto demuestra que el Huila está aprovechando las ventajas que ofrecen los acuerdos comerciales, no obstante aún existe un mayor margen de maniobra, especialmente con países como Estados Unidos, Canadá, algunos miembros de la Unión Europea y algunos países asiáticos, con los cuales el Huila presenta un alto grado de complementariedad comercial (potencialidad inmediata) en la comercialización de café.

En cuanto a los determinantes de la competitividad exportadora del café, los resultados muestran que la tasa de cambio se relaciona de forma positiva con el índice de ventajas comparativas, indicando que

\footnotetext{
${ }^{5}$ El $67,45 \%$ de las exportaciones del Huila son de café.
} 
una mayor tasa de cambio incentiva las exportaciones, y por lo tanto la competitividad de los productos con potencial exportador. Este resultado coincide con los encontrados por Cerda et al. (2011), quienes plantean que la relación de la competitividad y la tasa de cambio real es positiva en el caso de la uva de mesa chilena durante el periodo 1984-2004.

Así mismo, se evidencia una relación negativa entre la tasa de desempleo del Huila y el índice de competitividad, indicando la importancia de la producción y exportación del café en la generación de empleo, ya que el café es el tercer productor agropecuario que mayor demanda de jornales por hectárea cultivada presenta en el departamento del Huila.

El PIB (a precios corrientes) y precio del café, presentan una relación negativa con el índice de competitividad del café. El primer caso se explica, porque a partir del 2012 el Huila empezó a importar café; un aumentó en las importaciones, de acuerdo con las exportaciones netas, disminuye la producción (PIB). Estos resultados coinciden con los encontrados por Trejo y Alquicira (2001), para la industria del calzado en México durante los años 1985-1996. Con respecto al precio del café, un mayor precio implica un menor nivel de competitividad. Estos resultados también coinciden con Cerda et al. (2008), lo cual se explica a partir del alto nivel de dependencia de las exportaciones del café, pues el 67,45\% de las exportaciones del Huila son de café. Además, es importante precisar que el precio del café se determina a nivel internacional, con un alto nivel de independencia de las dinámicas internas del país.

\section{CONCLUSIONES}

El café es el principal producto de la economía huilense, de los productos agrícolas, es el que mayor empleo genera, es el bien que más se exporta en el Departamento, y que más aporta al PIB departamental. Alrededor del café, se ha generado todo un desarrolló cultural, que le ha permitido, transcender de generación en generación.

La presente investigación puso en evidencia la fuerte competitividad del Café del departamento del Huila, por lo tanto, el café producido en el Huila es un producto competitivo en las corrientes mundiales de intercambio de bienes. Un aspecto importante es que esta competitividad está creciendo, 
pues el Índice de Ventaja Comparativa Revelada viene aumentando durante los últimos años, lo que indica una tendencia creciente en el estado de exportación del café, es decir, el Huila está exportando más café, en términos relativos, al mundo, de lo que el Huila lo hace con el total de los demás productos. Esto demuestra una gran dependencia del sector cafetero en las exportaciones totales del departamento, produciendo poca diversificación de las exportaciones hacia otros productos, como los priorizados en la Agenda Interna de Competitividad del Huila.

Solo el $40 \%$ de los tratados de libre comercio, entre países y grupos de países, suscritos por Colombia, importan café de manera intensiva. Parece poco, pero sí la comparación se realiza, no por tratados sino por países, en el 53\% de los países con los que Colombia tiene algún vínculo comercial (materializado a través de un TLC, ya sea de forma independiente con cada país o de forma agregada con un grupo de países), importan de manera intensiva café. Es importante resaltar, que los países que no importan intensivamente café, son productores de café, como el caso de Costa Rica, México, los países del Mercosur, CAN, Alianza de Pacífico y Caricom, generalmente países latinoamericanos. Mientras que dentro de los países que importan café de manera significativa se encuentran Estados Unidos y Canadá, los países de la Unión Europa, y en Asía con países como Corea del Sur. Sin lugar a dudas, los TLC vigentes de Colombia, representan una gran oportunidad para este sector en específico y para la economía departamental, ya que, varios de estos países o grupo de países son grandes demandantes de este producto.

Teniendo en cuenta la complementariedad comercial del Huila con los países analizados, los principales destinos de las exportaciones de café del Huila son Cuba, Canadá, Estados Unidos y los grupos de países como la Unión Europea y el EFTA. Estos países se convierten en los posibles destinos más importantes del café exportado por el departamento del Huila. Es importante destacar que actualmente el Huila mantiene alguna relación comercial con estos países, siendo Estados Unidos el principal receptor del café del Huila. Sin embargo, estos resultados permiten al Huila priorizar sus esfuerzos exportadores hacia estos países o grupos de países como una oportunidad para aumentar el flujo comercial con cada uno de estos destinos, como es el caso de la Unión Europea hacia donde el Huila solo exporta el $24,17 \%$ del total de café. 
Un mayor tipo de cambio, afecta de manera positiva la competitividad exportadora del café huilense, pues una mayor tasa de cambio incentiva las exportaciones, ya que se recibirán más pesos por un dólar, lo que motivará a los productores y comercializadores de café a aumentar la producción y exportación.

El café es uno de los productos agrícolas que más empleos directos e indirectos genera, esto sumado a que es el producto con mayor nivel de exportación, y que más le aporte al PIB departamental, su impacto en la generación de empleo es considerable, lo que sustenta la relación inversa entre la tasa de desempleo y el índice de ventaja comparativa revelada.

A partir del 2012, el departamento del Huila, al igual que varios departamentos de Colombia, empieza a importar café, al tiempo que las exportaciones permanecían relativamente constantes. El impacto inmediato sobre la balanza comercial, fue una reducción de las exportaciones netas, al menos de café, lo que se tradujo en un menor crecimiento del PIB. De ahí, la relación negativa entre el índice de ventaja comparativa revelada y el PIB del Huila.

\section{REFERENCIAS}

(1) Arias, S. J. y Segura, R. O. (2004). Índice de ventaja comparativa revelada: un indicador del desempeño y de la competitividad productivo-comercial de un país. InterCambio Área de Comercio y Agronegocio, 4, 1-10. Recuperado de http://hdl.handle.net/11348/5885

(2) Balassa, B. (1965). Trade Liberalization and Revealed Comparative Advantage. The Manchester School of Economic and Social Studies, 33(2), 99-123. doi: 10.1111/j.1467-9957.1965.tb00050.x

(3) Cámara de Comercio de Neiva-CCN. (2015). Las Apuestas Productivas en el Plan Regional de Competitividad, Ciencia, Tecnología e Innovación del Huila. Recuperado de https://www.huila.gov.co/loader.php?IServicio=Tools2\&lTipo=descargas\&lFuncion=descargar\&idFile $=7440$

(4) Cámara de Comercio de Neiva-CCN. (2018). Informe de Coyuntura Económica. Recuperado de https://www.ccneiva.org/wp-content/uploads/2019/01/Informe-de-coyuntura-econ\%C3\%B3mica2018.pdf 
(5) Celaya, F. R. (2005). Los procesos de desarrollo agrícola en China y México: estudio comparativo a través de las ventajas comparativas reveladas en el período 1880-2000 (Tesis doctoral). Universidad de Colima, México.

(6) Cerda A., García, L., Aguilera, C. y Villagrán, L. (2011). Determinantes de la competitividad de las exportaciones de uva de mesa chilena, 1984-2004. Panorama Socioeconómico, 29(42), 62-72. Recuperado de https://www.redalyc.org/pdf/399/39922246004

(7) Cerda, A., Alvarado, M., García, L. y Aguirre, M. (2008). Determinantes de la competitividad de las exportaciones de vino chileno. Panorama Socioeconómico, 26(37), 172-181. Recuperado de https://www.redalyc.org/pdf/399/39911400008

(8) Cerquera, O. y Orjuela, C. (2015). El acompañamiento institucional en el desarrollo del sector cafetero colombiano. Revista Finanzas y Política Económica, 7(1), 169-191. doi: 10.14718/revfinanzpolitecon.2015.7.1.9

(9) Cerquera, O., Giraldo, J. y Córdoba, G. (2017). Ventaja comparativa revelada de los fertilizantes fosfatados del Departamento del Huila. Economía y Sociedad, 21(37), 51-74.

(10) Chudnovsky, D. y Porta, F. (1990). La competitividad internacional. Principales cuestiones conceptuales y metodológicas. Buenos Aires, Argentina: CENIT.

(11) Departamento Nacional de Planeación-DNP. (2007). Agenda Interna para la Productividad y Competitividad documento Regional Hecuperado de https://www.huila.gov.co/publicaciones/5078/oficina-de-productividad-ycompetitividad/descargar.php?idFile $=7327$

(12) Federación Nacional de Cafeteros-FNC. (2018). Informe De Gestión. Recuperado de https://www.federaciondecafeteros.org/static/files/Informe_Gestion_2018.pdf

(13) Khaksar, H. Y. (2014). Determining Revealed Comparative Advantage and Target Markets for Iran's Stone Fruits. Journal of Agricultural Science and Technology, 16(2), 253-264. Recuperado de http://jast.modares.ac.ir/article-23-9116-en.html

(14) Liesner, H. (1958). The European Common Market and British Industry. Economic Journal, 68(270), 302-316.

(15) Machado, A. (2001). El café en Colombia a principios del siglo XX. En Misas A. (Ed.), Desarrollo económico y social en Colombia siglo XX (pp.77-98). Bogotá, Colombia: Editorial Universidad Nacional de Colombia, sede Bogotá.

(16) Ministerio de Agricultura y Desarrollo Rural. (2019). Bullets Cadena de Café. Recuperado de https://sioc.minagricultura.gov.co/Cafe/Documentos/2019-03-30\%20Cifras\%20Sectoriales.pdf

(17) Obadi, S. y Korcek, M. (2016). The Revealed Comparative Advantage and Competitiveness of the EU's International Trade vis à vis the USA. Ekonomicky casopis, 64(5), 397-422. 
(18) Rendón, A. T. y Morales, A. A. (2001). Modelos econométricos para analizar el impacto de variables económicas en la competitividad de la industria del calzado. Política y Cultura, 15, 263-285. Recuperado de https://www.redalyc.org/articulo.oa?id=26701513

(19) Scott, L. y Vollrath, T. (1992). Global competitive advantages and overall bilateral complementary in agriculture. Washington, D. C., Estados Unidos: Deptarment of Agriculture, Economic Research Service.

(20) Tsakok, I. (1990). Agricultural Price Policy: Practitioner's Guide to Partial-Equilibrium Analysis. Nueva York, Estados Unidos: Cornell University Press.

(21) Verdoy, P. J., Mahiques, J. M. y Pellicer, S. (2006). Manual de control estadístico de calidad: teoría y aplicaciones. Castellón de la Plana, España: Publicaciones de la Universitat Jaume I.

(22) Villablanca, H. M. (2014). Análisis de la competitividad del vino chileno en los mercados de Reino Unido y Estados Unidos (Tesis de maestría). Universidad del Bío-Bío, Chile.

(23) Vollrath, T. (1991). A theoretical evaluation of alternative trade intensity measures of revealed comparative advantage. Weltwirtschaftliches Archiv, 127(2), 265-280.

Cómo citar este artículo: Cerquera, O., Pérez, V. y Sierra, J. (2020). Análisis de la competitividad de las exportaciones del café del Huila. Tendencias, 21(2), 19-44. https://doi.org/10.22267/rtend.202102.139 